\title{
El lenguaje periodístico del deporte en el idioma español del siglo XXI
}

\author{
Jesús CASTAÑón RODRÍGUEZ \\ Idiomaydeporte.com \\ info@idiomaydeporte.com
}

Recibido: 2 de febrero de 2012.

Aceptado: 10 de abril de 2012.

\section{Resumen}

La globalización del deporte ha generado numerosos cambios en su comunicación especializada, un ámbito cuyo estudio está vinculado a facetas de historia cultural, sociedad global y difusión de valores. En el español del siglo XXI, este proceso ha comprendido nuevos temas, estructuras y rasgos en la codificación lingüística de noticias y, también, aspectos de observación, reflexión institucional, recreación artística, acceso a la información, investigación universitaria, trabajo multilingüe, presencia en congresos, organismos internacionales, o en la enseñanza y el desarrollo de nuevos estudios.

Palabras clave: Ciencias sociales; comunicación deportiva; globalización; hispanismo; lenguaje y jerga; periodismo.

\section{The Journalese of the Sport in Spanish Language of the 21th Century}

\begin{abstract}
The globalization of sport has generated numerous changes in its specialist communication, an area whose study is linked to facets of history of culture, global society, and dissemination of values. In the Spanish language of the twenty-first century, this process has included new topics, structures and features in the linguistic encoding of news, and also aspects of observation, institutional reflection, artistic work, access to information, university research, multilingual work, presence in congresses, international organizations or in the teaching and development of new studies.
\end{abstract}

Key words: Social science; sports journalism; globalization; Hispanic studies; language and jargon; mass media.

\section{Referencia normalizada}

Castañón Rodríguez, J. (2012). El lenguaje periodístico del deporte en el idioma español del siglo XXI. Historia y Comunicación Social, Vol. 17, páginas 343-358.

Sumario: 1. Introducción. 1.1. Estado de la cuestión. 1.2. Metodología. 2. La codificación lingüística de la comunicación. 3. Apuntes sobre el idioma español en el deporte. 3.1. La mirada del idioma hacia la comunicación deportiva. 3.2. La mirada de la comunicación deportiva hacia el idioma. 4. Conclusión. 5. Bibliografía. 


\section{Introducción}

\subsection{Estado de la cuestión}

Este artículo se propone analizar algunos de los principales aspectos de la situación actual del lenguaje periodístico del deporte en español en relación con los procesos de globalización desarrollados desde finales del siglo XX. La mundialización deportiva ha traído cambios relacionados con la concentración de capitales, la homogeneización cultural, una creciente información de todos los torneos internacionales, la transformación de las entidades deportivas en grandes corporaciones y la revisión de su identidad por motivos mercantiles, tal y como ha ocurrido en camisetas, vestimentas, salas de prensa y nombres de estadios y campeonatos. Y en su comunicación especializada han surgido nuevas formas entre los diferentes estamentos del deporte, como consecuencia de las grandes emigraciones de jugadores y entrenadores, y las entidades han forjado sus propias estrategias comunicativas para combinar la proyección de su imagen en la sociedad, mejorar la relación con públicos internos y externos y crear climas favorables de opinión al consumo de todo tipo de productos.

En el siglo XXI, las expresiones del lenguaje periodístico del deporte han establecido recorridos sin fronteras y un viaje oeste-este del Atlántico. En una primera fase, hasta 2004, la comunicación deportiva elaboró contenidos informativos y de entretenimiento orientados a relacionar, informar y sugerir mediante una forma de redacción que combinaba una nueva ordenación espacial y una organización interactiva con textos breves, hipertextos, géneros iconográficos, ideas sonoras y una escritura modular para su aprovechamiento funcional. Fue una novedad que obligó a las instituciones deportivas y de la comunicación a reflexionar sobre la evolución histórica de su difusión y sobre diversos aspectos lingüísticos. Fue el caso del Comité Olímpico Internacional que, en 1998, para facilitar la comunicación entre deportistas, técnicos de la radio y la televisión, traductores e intérpretes de conferencias, reflexionó sobre el papel del comentario deportivo en la exposición Broadcasting the Olympics, la mesa redonda La Télévision et les Jeux Olympiques, el simposio de la Semaine de la Radio-Télévision Olympique'98 y editó una obra terminológica de referencia que acogía voces relacionadas con el Comité Olímpico Internacional, los deportes olímpicos, la medicina, los medios de comunicación y diversas siglas y abreviaturas (Katz, 1998).

Al final del primer decenio de la presente centuria, el idioma del deporte ha despertado un creciente interés para las ciencias sociales ya que las formas comunicativas del deporte no sólo atienden a la práctica individual, asociativa o profesional. Han desarrollado una dimensión cultural y social que comprende aspectos de integración, calidad de vida y transmisión de valores en una población con disposiciones afectivas y de expresión de su intensidad emotiva, tanto al mirar como al practicar deportes. Y han ampliado su influencia social al establecer relación con cuestiones especializadas en información, investigación científica, documentación, educación, salud, turismo, mundo empresarial o recurso de redacción periodística de otras áreas informativas, entre otros. 


\subsection{Metodología}

La metodología adoptada en este artículo selecciona los principales componentes de la globalización comunicativa de estas formas de expresión. Ofrece una mirada del deporte como observatorio de las tendencias lingüísticas más actuales por su originalidad al crear términos procedentes de la acción deportiva, los pasillos del poder, las emociones de la grada y las formas mediáticas. Destaca cómo esta reflexión lingüística sobre el español del deporte como lengua de comunicación internacional no sólo se ha visto reflejada en diccionarios y obras de referencia, sino que también ha comprendido aspectos de terminología técnica, lenguaje periodístico, análisis del discurso, emociones y trabajo multilingüe con el fin de atender a diferentes aspectos ligados al contacto entre las diferentes variedades, las migraciones, el turismo, el aprendizaje de lenguas o los procesos de globalización relacionados con la identidad. Y además, registra una amplia bibliografía, elaborada en el actual siglo en 18 países diferentes, que incluye referencias de estudiosos de países de habla hispana y de hispanistas procedentes de países de otras lenguas.

\section{La codificación lingüística de la comunicación}

El contenido simbólico de la comunicación deportiva cuenta con una redacción periodística en la que intervienen diversas disciplinas, sistemas especiales de signos, estructuras expresivas y de contenidos... susceptibles de estudio. Desde la primera mitad del primer decenio del siglo XXI se ha registrado una constante diversificación de la actividad física y el deporte, su asociación a agencias de publicidad, eventos comerciales y movimientos asociativos, su creciente relación con el turismo y la plena incorporación de la mujer (Aragón et al., 2009; Barrero, 2010; Galfaro et al., 2010; López, 2011 y Vigara, 2009).

Han surgido nuevas estructuras para atender a un cambio generacional. La extensión de la alta competición a la edad adolescente, con la puesta en marcha de los Juegos Olímpicos de la Juventud para participantes de entre 14 y 18 años y periodistas de 18 a 25, ha recurrido a una comunicación que combina el deporte con otros elementos sociales gracias a aplicaciones de medios digitales y redes sociales para participar, crear y compartir información. Ha dado paso a un tiempo de intercambio de opiniones y experiencias en un diálogo de ideas, culturas y tradiciones en el que las nuevas tecnologías difunden los beneficios de estilo de vida sano, la lucha contra el dopaje, la carrera deportiva y su gestión, la labor social del deportista en su comunidad, las relaciones con los medios de comunicación, los efectos de los medios de comunicación digitales y la exaltación de valores olímpicos.

Este conocimiento tecnológico ha desarrollado productos que se actualizan desde plataformas de edición, a la hora de abordar temas en profundidad o de ofrecer puntos de vista complementarios mediante visores biográficos y temáticos, y desde plataformas de gestión de noticias por medio de contenidos por el teléfono móvil, noticias por correo electrónico, servicios de sindicación de noticias, archivos de 
sonidos, alertas en el escritorio del ordenador, visores monoformato y multiformato que presentan flashes de noticias y módulos de contenidos HTML integrados en otra web. Ha buscado el impacto social y ha presentado una información a toda velocidad para satisfacer el entusiasmo global de un usuario que convierte al deportista y a las entidades en iconos, marcas y personajes de la cultura mediática y al deporte en un pretexto para representar otras historias, mitos, valores, prioridades, esperanzas, sueños y aspiraciones (Boyle y Haynes, 2009). Su codificación ha formado una nueva sintaxis narrativa que afecta a la captación de información, redacción, elaboración y presentación de contenidos, así como a su edición y publicación. Lingüísticamente, se ha caracterizado por elaborar una información esencial en alta velocidad con microtextos de lectura rápida y fácil, en la que adquieren gran importancia la espontaneidad y la oralización, la precisión terminológica, el cuidado de las traducciones, el uso de hispanoamericanismos léxicos, las transcripciones de nombres desde diferentes alfabetos, el empleo de términos genéricos frente a los localismos, el resumen del hecho deportivo y sus emociones con titulares con juegos de palabras y sentido del humor y la descripción de acontecimientos con un léxico apto para audiencias no especializadas. Es un panorama que se completa con la consulta de fuentes foráneas y la redacción con una estructura modular susceptible de ser automatizada, modificada y adaptada a las necesidades de diferentes productos (Agencia Efe, 2011; Castañón, 2009).

Esta evolución ha llevado también a una creciente reflexión en tres apartados, que también afecta al idioma. En primer lugar, la relación entre historia cultural y medios de comunicación ha entendido que el deporte acoge un viaje de lo local a lo internacional capaz de generar una cultura variada que influye en los comportamientos individuales y colectivos, a partir de tres grandes bloques temáticos (Attali, 2010). Se centra la mirada en cuestiones de deporte, memoria y sociedad incluyendo sus manifestaciones artísticas, como es el caso de la labor de la editorial Atlantica (Lunzenfichter, 2004; Marchand, 2002, 2003 y 2004); del Centre de Recherche sur l' Espagne Contemporaine XVIIIe - XIXe - XXe siècles (CREC) de la Université Paris III-Nouvelle Sorbonne que estudia los intercambios e interferencias de historia cultural entre España y Europa (Uría, 2009); de la Universidad de Grenoble y su Laboratorio de Deporte y Entorno Social que analizan sus componentes, representaciones compartidas y retórica a la hora de ser elemento co-productor de la transformación social; o del Équipe interdisciplinaire de recherche sur l'image satirique (EIRIS) de la Universidad de la Bretaña Occidental que investiga sobre la imagen satírica con enfoques lingüísticos, literarios, históricos, estéticos, filosóficos, psicólogicos, semióticos y en relación con la historia del arte. Además, se aborda la difusión de ideas positivas para la cultura de masas, el conocimiento de la actualidad y la construcción redaccional a la hora de crear mitos y símbolos vinculados a la modernidad, el progreso y el gusto del periodismo por la literatura de tema deportivo (Tétart y Villaret, 2010). Y también, se registra el paso de la visión humanista del deporte a una evolución mercantil marcada por los derechos de la transmisión audiovisual y las nuevas tecnologías con retos como la renovación ética, la necesidad de una formación especializada para el periodista y el establecimiento de nuevas rela- 
ciones con la universidad y el mercado publicitario (Lunzenfichter, 2004).

En segundo lugar, el estudio del deporte en la sociedad global ha alcanzado gran notoriedad en Estados Unidos y el Reino Unido, lugares en los que se ha analizado la transformación y crecimiento del deporte con sus cambios en la actuación de los deportistas, la creciente competencia, el desarrollo de las ciencias del deporte y el paso del mito del amateurismo a la exaltación de nuevas actitudes para la salud y las nuevas aplicaciones del legado olímpico y paralímpico (Rogan y Rogan, 2011). Se ha ocupado de generar estudios regionales de las dimensiones política, cultural, emotiva y estética del deporte moderno en el mundo, gracias a publicaciones como The International Journal of the History of Sport y la colección de títulos de la serie Sport in the Global Society, publicada por la editorial Routledge, bajo la coordinación del historiador británico James Anthony Mangan y de los profesores universitarios Boria Majumdar y Mark Dyerson.

$\mathrm{Y}$ en tercer lugar, desde finales del siglo XX se ha destacado el valor social del deporte, tanto en su exaltación del internacionalismo y la interculturalidad, como en relación con la educación, la sanidad y la calidad de vida (Preuss et al., 2011). La extensión de la alta competición a edad adolescente ha hecho que el Comité Olímpico Internacional asiente esta construcción social en siete ejes a los que se asocian diversos valores: fortalecer cuerpos y mentes, enseñar a respetar reglas, respetar al adversario, desarrollar habilidades sociales y ayudar a la integración, aportar identidad, dar alegría y orgullo y mejorar la salud. En esta tarea, las fundaciones deportivas de los clubes han transmitido esta cultura de valores favorables a una vida sana y equilibrada en lo intelectual, en lo físico y en lo emocional, han eliminado diferencias de género, religión o raza, han favorecido la integración social y el desarrollo del voluntariado y han resaltado la repercusión de la educación física en el bienestar.

En este marco general, el estudio social del deporte en idioma español, solo en el siglo actual, ha generado investigación que destaca el impacto del deporte moderno en la vida política, social y cultural, las expresiones comunicativas, los modelos deportivos que sugieren los medios en la práctica deportiva, la consideración del deporte como índice del nivel de desarrollo y de calidad de vida, el desarrollo de actitudes favorables a la convivencia entre gentes procedentes de diferentes culturas, los códigos compartidos para la vivencia apasionada con sus espacios, tiempos y memoria subjetiva y, en el olimpismo, ha hecho especial hincapié en la gestión de información y documentación, las ceremonias, las olimpiadas culturales y los legados de los Juegos Olímpicos a través de su relación con la televisión, los nuevos medios, el voluntariado, el género, el multiculturalismo, la economía, la educación y la cultura (Aisenstein et al., 2001; Caspistegui y Walton, 2001; Crolley y Hand, 2002; Fernández et al., 2011; González, 2008; Marín 2005; Medina y Sánchez, 2003; Rivera, 2010; Ruiz, 2010; Solar y Reguera, 2008). Es una tarea que se ha desarrollado desde el último tercio del siglo XX, de forma especial, en Argentina, España, Estados Unidos y México y en la que han destacado, por su continuidad, el Centro de Estudios Olímpicos de Barcelona o el Área Interdisciplinaria de Estudios del Deporte de la Universidad de Buenos Aires, entre otros. 


\section{Apuntes sobre el idioma español en el deporte}

El crecimiento del deporte ha hecho que diversos ámbitos hayan mantenido diferentes puntos de vista por el uso del lenguaje periodístico.

\subsection{La mirada del idioma hacia la comunicación deportiva}

La visión especializada de la lengua hacia la norma estándar empleada en los medios de comunicación, cuenta en la actualidad con siete centros de interés que ya se vienen desarrollando desde el siglo anterior.

Primero, la observación lingüística de los usos del español actual con orientaciones hacia el decoro y la crítica de desbarajustes semánticos, burdéganos, incorrecciones e impropiedades. En España dio sus primeros pasos en 1903 y, a partir de 1975 y en este siglo, se ha extendido a Brasil, España, Honduras, México y Uruguay gracias, entre otras, a secciones de carácter general como "El dardo en la palabra" y "El nuevo dardo en la palabra" de Fernando Lázaro Carreter, "Minucias del lenguaje" de José Guadalupe Moreno de Alba, las colaboraciones de Gregorio Salvador recogidas en la recopilación El fútbol y la vida, y también al desarrollo de secciones específicas como "Palabras mayores" de Basketconfidencial, "Idioma del deporte" de Vilma Castillo o "El español en el deporte", "Literatura y Lingüística del deporte", "Palabras en juego" e "Hinchas del idioma".

Segundo, la reflexión institucional sobre el uso del español del deporte en los medios de comunicación, en marcha desde 1908, ha generado en los últimos años una creciente reflexión por su repercusión social en la renovación general del idioma y su conversión en vivencia cultural, en recurso para la redacción de otras áreas informativas y en elemento de persuasión para la gestión del trabajo en equipo y el liderazgo. Se ha centrado en el registro de voces, la elaboración de orientaciones léxicas y gramaticales, la descripción del uso actual y la incorporación de trabajos terminológicos del deporte a los recursos lingüísticos de actividades de difusión y promoción de la tecnología lingüística. Desde el año 2000 hasta el presente, han participado académicos de Argentina (Peltzer, 2007; Zorrilla, 2004), Colombia (Samper, 2001), España (García Yebra, 2003; Lázaro Carreter, 2003; Lorenzo, 2008; Salvador, 2006, 2007a y 2007 b), Estados Unidos (Gómez Font, 2004 y 2006) o México (Moreno, 2003). Este proceso se ha concretado en obras de referencia que centran su atención en adaptaciones gráficas, el uso del género, la formación de plurales, la existencias de equivalencias, el empleo de otros términos como sinónimos, las recomendaciones ortográficas y el comentario de dudas y errores más comunes (Asociación de Academias de la Lengua Española, 2010; Fundación del Español Urgente, 2008; Real Academia Española, 2001 y 2006; Real Academia Española y Asociación de Academias de la Lengua Española, 2005). Y además, las diferentes ediciones del Congreso Internacional de la Lengua Española llamaron la atención sobre la plena incorporación institucional del idioma del deporte, su consideración como ámbito que recoge las tendencias más novedosas del español actual y otros aspectos más específicos como el uso de terminología opaca, el lenguaje de los 
noticiarios de televisión en Chile, el léxico de la prensa en España, la relación entre literatura y periodismo deportivo y el tratamiento del lenguaje periodístico del deporte como lengua espectáculo.

Tercero, la dimensión artística del cuerpo a través de la creatividad viene siendo estudiada y fomentada desde 1919 por la entidad gala Pluma-Palette Club y su continuadora la Association des Écrivains Sportifs. En el caso del español, alcanza gran notoriedad a partir de los autores literarios de las vanguardias del siglo XX y, desde 1967, el deporte se convierte en una ocasión permanente para el arte al haber dado lugar a numerosos estudios, antologías generales, recopilaciones de poesía, teatro y relatos, exposiciones y encuentros de escritores y críticos.

Cuarto, guarda relación con el acceso a la documentación e información deportiva, gracias a la labor en Austria del Buró para Documentación e Información (BDI) desde 1959, y de la Asociación Internacional para la Información Deportiva (IASI) que han confeccionado terminología deportiva y tesauros para la identificación, descripción y difusión de la información deportiva. Una tarea en la que ha destacado la constancia del Consejo Superior de Deportes y del Instituto Andaluz del Deporte, cuyas publicaciones y orientaciones han sido adoptadas por numerosos organismos deportivos de países de habla hispana.

Quinto, desde 1954 la investigación universitaria ha comprendido 30 trabajos de investigación, de los que 19 corresponden al siglo XXI y han sido elaborados en ocho países: Colombia, Cuba, España, Guatemala, Italia, República Checa, Suecia y Venezuela (Bazán, 2003; Castro, 2003; Díaz, 2001; Díaz, 2004; Dulíková, 2008; García, 2000; González, 2010; Hansson, 2005; Herráez, 2002; Isasi, 2006; Lan, 2004; Mapelli, 2000; Morales, 2009; Nomdedeu, 2004; Paredes, 2002; Riera, 2003; Rojas, 2008 y 2010; Teruel, 2006).

Sexto, la internacionalización del deporte ha creado textos de referencia para facilitar la comunicación entre deportistas y periodistas, técnicos de radio y televisión, traductores e intérpretes de conferencias en la sociedad de la información multilingüe. El español figura en obras de este tipo desde 1960 con vocabularios para la alta competición, gracias a obras de equivalencias de términos entre varios idiomas para los Juegos Olímpicos celebrados en México, Múnich, Montréal, Seúl y Barcelona, así como para la Copa del Mundo de Fútbol. Esta producción sería posteriormente aprovechada, entre 1996 y 2006, por los comités organizadores de los Juegos Olímpicos de Verano en Atlanta, Sidney y Pekín, y por la Copa del Mundo de Fútbol en Corea y Japón. También ha orientado sobre transcripción de nombres desde alfabetos no latinos y dudas en expresiones periodísticas, ha proporcionado formación lingüística especializada para periodistas, traductores y voluntarios en Cuba y España, ha desarrollado aplicaciones para el aprendizaje y el ocio, ha favorecido la comprensión de términos en el recinto de competición y de las noticias de los medios de comunicación y ha llevado a cabo análisis comparativo entre diferentes lenguas (Hernán-Gómez, 2009; Lavric et al., 2008; Ordoño, 2004; Scotini, 2006; Stassinet, 2002; Termcat 2010).

Y séptimo, desde los años noventa se ha reflexionado de forma constante sobre el lenguaje deportivo, entre otros, en congresos, seminarios y cursos celebrados en 
Argentina, España, Francia, Italia y México. Es el caso, entre otros, de El neologismo necesario (1991), El idioma español en el deporte (1992), Seminario de Corrección Lingüística Corrección de textos en la prensa escrita (1996 y 1998), Encuentro sobre el Idioma Español en el Deporte (1997), Jornadas de Documentación e Información Deportiva (1999), Conference on co-operation in the field of terminology in Europe (1999), Encuentro Deporte y Ciencias Sociales (2000), Expresiones comunicativas del deporte (2001), Encuentro sobre el idioma español en los medios de comunicación (2002), Acerca de las audiencias deportivas (2002), Expresiones deportivas como metáforas en la vida diaria (2003), La influencia mediática en el deporte (2003), Encuentro de la Asociación Mexicana de Investigadores de la Comunicación (2004), Curso de Humanidades Contemporáneas El español y los medios de comunicación (2005), Ciclo de Conferencias de la Fundación del Español Urgente (2006), El idioma español en el periodismo deportivo (2006), El español en los medios de comunicación (2006), Seminario de Lengua Española y Medios de Comunicación (2006 y 2010), Il linguaggio dello sport, la comunicazione e la scuola (2008), Cosmopoética (2009), El deporte en la radio: lenguaje y formatos (2009) y Comunicación y deporte en la era global (2009) y Encuentro de Escritores y Críticos de las Letras Españolas en Verines (2010) y Congreso Internacional Virtual de Educación Lectora CIVEL: libros, comprensión lectora y biblioteca (2011).

De forma específica, en el siglo XXI cabe destacar la aparición de tres nuevos centros de interés. Primero, el apoyo institucional para favorecer la presencia internacional del español en los principales organismos del deporte, como el intento de reconocimiento del idioma español como lengua oficial del Comité Olímpico Internacional que fue impulsado en 2001 por el Comité Olímpico Cubano.

Segundo, la presencia del lenguaje periodístico del deporte en el ámbito educativo. De una parte, en la enseñanza reglada, esta aportación ha llegado al nivel universitario con una evolución que va de las primeras actividades deportivas y culturales desde 1968 hasta su presencia en maestrías de periodismo desde 2001. También, se ha incorporado a la enseñanza del español para extranjeros y a la educación secundaria a la hora de desarrollar varias habilidades comunicativas, la mejora de la comprensión de la lengua de la sociedad de acogida con juegos multiculturales e interculturales, el análisis crítico de los mensajes de los medios de comunicación, el estudio de los microlenguajes y la reflexión sobre los mecanismos de formación de palabras en la lengua general y el lenguaje periodístico (Blecua et al., 2007; Gálvez et al., 2007; Lleixá y Soler, 2004; Pilmark y Hakanson, 2011; Sánchez, 2005). Y en el bachillerato internacional se ha relacionado el deporte y su lenguaje con un estilo de vida sana y equilibrada en lo intelectual, lo físico y lo emocional junto el estudio del contexto cultural del deporte, la influencia que recibe de los medios de comunicación y la valoración de la forma precisa y apropiada en el uso de terminología como un criterio de evaluación que se aplica a conocimientos de principios, conceptos, reglas, técnicas y estrategias (Organización del Bachillerato Internacional, 2007). Y de otra parte, en la enseñanza no reglada, el deporte ha promocionado valores educativos orientados al desarrollo de la persona y a favorecer el aprendizaje de idiomas con un entorno eficiente, rápido y divertido mediante un 
modelo seductor que convierte la experiencia deportiva de campamentos culturales y de ocio en un relato de aventuras humanas, en un elemento generador de empleo y en una forma de relacionarse con él como trabajo, arte o negocio (Secretaria de Educação Continuada, Alfabetização e Diversidade, 2007).

Finalmente, un tercer aspecto hace referencia al desarrollo de nuevos enfoques en los estudios sobre el lenguaje deportivo, según se ha reflexionado en Alemania, Austria, España, Italia y Suiza. Comprenden las lenguas de especialidad y su relación con la necesidad de formar profesionales especializados con un bagaje lingüístico específico, así como el problema de los extranjerismos que relaciona el español del deporte con otras 39 lenguas (Calvi y Chierichetti, 2006; Díaz, 2010; Gutiérrez, 2006; Hernán-Gómez, 2009; Lavric et al., 2008; Loza y Castañón, 2010; Martinell, 2004; Navarro et al., 2008; Tillman-Weleda, 2008; Weinrich, 2007).

\subsection{La mirada de la comunicación deportiva hacia el idioma}

La visión de los medios de comunicación hacia el mundo lingüístico ha generado dos ejes de actuación: la demanda de formación especializada y la reflexión sobre las relaciones culturales.

Primero, la solicitud de formación lingüística en español, especializada en deportes, ha sido demandada en España, Guatemala, México y Puerto Rico, al rebufo de una tendencia que también se ha producido en Brasil, Francia y Reino Unido. Supera el tópico de la despreocupación de los periodistas deportivos por el buen uso del lenguaje, ya que han venido desarrollando desde el siglo XX aspectos relacionados con: animación publicitaria, creatividad de sonidos y de imágenes, cultura, diccionarios y enciclopedias, formación, investigación universitaria, libros de estilo, reflexión en cursos de verano y congresos, y elaboración de trabajos sobre términos extranjeros. Reconoce su forma de expresión singular, busca el equilibrio entre el lenguaje informativo y el lenguaje emocional, tiene conciencia de la multiplicación de la banalización léxica con las nuevas tecnologías, fomenta el buen uso de terminología específica, comenta la presencia de los lenguajes jurídico y médico y muestra su crítica hacia el lenguaje violento, el uso de extranjerismos, las expresiones belicistas, los tecnicismos, los tópicos, las acronimias y otras modalidades (Alcoba, 2005; Barbeiro y Rangel, 2006; Barrero, 2008 y 2009, Castañón, 2011; Castañón y Castañón, 2006; Esteve y Fernández, 2009; Lunzenfichter, 2004; Marrero, 2010; Paniagua, 2009; Steen, 2008; Vilas, 2005).

En el ámbito del español se ha buscado una mejor redacción cotidiana, tras un largo proceso. En 1991, se solicitó un libro de redacción único en el congreso El neologismo necesario, se impulsó en 1997 con el Proyecto Zacatecas y se concretó en 2005 en el Diccionario Panhispánico de dudas para aportar orientaciones sobre adaptaciones gráficas, uso del género, formación de plurales, equivalencias, uso de sinónimos y de vulgarismos procedentes de la jerga periodística, recomendaciones ortográficas y comentarios de dudas y errores más comunes. Dejaba atrás la promoción del uso de un español neutro con normas fonéticas, diccionarios de palabras equívocas y equivalencias de localismos, para dar paso al registro de dudas grafemá- 
ticas en topónimos y gentilicios, siglas de federaciones, organismos, ligas y asociaciones profesionales, abreviaturas de países, expresiones tópicas, alternativas a construcciones sintácticas con influencias extranjerizantes y la promoción de valores culturales del mundo hispanohablante que eviten el forofismo, las expresiones racistas, xenófobas, violentas, vulgares o provocadoras, los estereotipos chovinistas y étnicos, la separación en un formato especial del humorismo y la ironía en la presentación de informaciones, la adulación innecesaria y sin fundamento... (Allas y Díaz, 2004; Asociación de la Prensa de Madrid, 2007; Rojas, 2005 y 2011).

Esta incipiente labor ha atendido a un complejo panorama de diversidad en el que confluyen variadas distribuciones lingüísticas, deportivas y mediáticas. Lo lingüístico presenta numerosas variedades que llevan a una norma como conjunto de preferencias vigentes en una comunidad de hablantes que se puede clasificar en cinco zonas, en ámbitos con vocabulario semejante que abarcarían México, capitales antillanas y Caracas, Centroamérica, Bogotá-Lima-Quito-La Paz y Asunción-Buenos Aires-Montevideo; o en ocho áreas diferentes, según establecen las últimas publicaciones académicas con un enfoque panhispánico, que comprenderían Chile, Río de la Plata, Área Andina, Caribe Continental, México y Centroamérica, Antillas, Estados Unidos y Filipinas y España (Moreno, 1001 y 2007; Real Academia Española y Asociación de Academias de la Lengua Española, 2009). Aunque aún es posible recorrer más camino, numerosas formas de expresión del deporte se han visto incorporadas a obras de referencia con términos y siglas que hacen referencia a expresiones deportivas de carácter general, acepciones sobre apuestas deportivas y de otras actividades, voces específicas sobre elementos, indumentaria y lances del juego de 47 disciplinas deportivas diferentes, denominaciones populares que reflejan la vivencia social de aficiones y equipos destacados de béisbol y fútbol, expresiones de la lengua común provenientes del lenguaje especial del deporte y acrónimos de instituciones, entidades y federaciones (Asociación de Academias de la Lengua Española, 2010). En lo mediático, la norma estándar del lenguaje periodístico del deporte ha abordado cuestiones relacionadas con la responsabilidad lingüística de los periodistas, la eficacia comunicativa del estilo informativo, la labor del editor de estilo y su lucha entre lo que demandan el mundo académico y la práctica diaria de la comunicación, el tratamiento de la terminología especializada, la orientación profesional del libro de estilo y la confección de obras que tengan en cuenta la norma policéntrica del español (Carriazo, 2008; Martínez Albertos, 2008). Es un panorama de variedades que combina unas rutas de difusión que han atendido a varias fases de migraciones de población: los rumbos este-oeste del Atlántico y sur-norte de América que, entre 1938 y 1966, compartieron información en cadena y exaltaban sentimientos de liberación por el esfuerzo y de ver cumplidos los sueños en tierras remotas; una dirección norte-sur de América, de 1974 a 1994, que convirtió el deporte una forma de expansión afectiva para vivir en otra cultura gracias a una información sobre resultados de grandes deportistas latinoamericanos por todo el mundo y de las actividades de la comunidad latina en el país de llegada; y, desde 1994 hasta la actualidad, se dio paso a recorridos sin fronteras y se trazó una ruta oeste-este del Atlántico para el intercambio de información a toda velocidad con la 
participación de hinchas, deportistas y periodistas. Y en lo deportivo también se manifiesta esta variedad, ya que el mapa de su vivencia destaca el predominio del fútbol en los países de Sudamérica, del béisbol en las islas caribeñas de influencia española, en la mexicana Península de Yucatán y en Venezuela, del críquet en las islas de influencia anglosajona, del baloncesto en Argentina, Cuba y Brasil, del boxeo en Centroamérica y Caribe... Todo ello tendrá diversas repercusiones en los usos del idioma, como es el caso de una mayor o menor presencia de extranjerismos en función de si en la difusión de un deporte se ha realizado o no desde un país de habla hispana.

Y segundo, se rechaza la incompatibilidad entre cultura y deporte. Si sus antecedentes se remontan a Francia con los Juegos Olímpicos de 1924, en el caso del idioma español se establecen, actualmente, estructuras especiales para este tipo de textos. Deporte y literatura conforman una cancha múltiple en la que se entrecruzan la producción, la comunicación, la mitología, el conocimiento y la promoción de la lectura y de las letras. Su creciente relación comprende cuatro apartados: las antologías literarias; el análisis de mecanismos de cultura popular que intervienen en su puesta en escena y el acceso a diferentes recursos; los estudios sobre la producción literaria especializada; y, finalmente, los aspectos de didáctica ligados a la adquisición de competencias lingüísticas, la enseñanza del español como lengua extranjera, la literatura infantil y juvenil y la relación entre arte, historia y deporte en procesos de enseñanza aprendizaje para alumnado universitario y de enseñanza primaria y secundaria (Castañón y Rodríguez, 1997; Ministerio de Cultura et al. 2010, Morelli, 2000; Paniagua, 2009; Wood 2007 y Wood et al., 2008).

\section{Conclusión}

El siglo XXI constituye un reto para el lenguaje periodístico del deporte en español, dada su incidencia en la renovación de la lengua general y su gran influencia social en una gran extensión territorial.

Sus tradicionales formas expresivas para unir el espectáculo deportivo, las emociones del público y las recreaciones artísticas de los acontecimientos han alcanzado una notable variedad y riqueza. Y en un nuevo paso, su renovación en esta centuria traspasa los límites de los recintos deportivos, lleva su creación a la plena participación de la sociedad, se extiende por entornos tecnológicos que eliminan fronteras y horarios, y crea términos que relacionan el deporte con la salud y la calidad de vida, la transmisión de valores sociales y culturales, la economía, la mejora de los procesos de aprendizaje en la educación...

Este constate crecimiento no debería olvidar varios aspectos en la evolución del lenguaje periodístico: el pluricentrismo lingüístico, deportivo y mediático de los países de habla hispana, el trabajo multilingüe para acceder a otras lenguas empleadas en los acontecimientos deportivos tanto en el desarrollo de competiciones como en el uso de fuentes documentales, el acercamiento a las diferentes variedades del español en el deporte y el aprovechamiento de las posibilidades de las nuevas 
tecnologías en una redacción periodística en la que la autoridad de comunicación no corresponde a la lengua puesto que se informa con códigos verbales y sugiere con códigos no verbales.

El lenguaje periodístico del deporte ya no es sólo un juego, se ha convertido en una necesidad de la sociedad contemporánea.

\section{Bibliografía}

AGENCIA EFE (2011). Libro del estilo urgente. Barcelona: Galaxia Gutenberg y Círculo de Lectores.

AISENSTEIN, A.; DI GIANO, R.; FRYDENBERG, J; GUTERMAN, T. (comp.) (2001): Estudios sobre deporte. Buenos Aires: Libros del Rojas y Universidad de Buenos Aires.

ALCOBA, A. (2005). Periodismo deportivo. Madrid: Síntesis.

ALLAS J. M.; DÍAZ, L. C. (2004). Libro de estilo. Sevilla: Canal Sur.

ARAGÓN, M.; EURRUTIA, M.; PLANELlES, M.; RUIZ, F. (2009). Diccionario de términos del turismo. Barcelona: Ariel.

ASOCIACIÓN DE ACADEMIAS DE LA LENGUA ESPAÑOLA (2010). Diccionario de americanismos. Madrid: Santillana.

ASOCIACIÓN DE LA PRENSA DE MADRID (2007). Directrices editoriales. Valores $y$ criterios de la $B B C$. Madrid: Asociación de la Prensa de Madrid.

ATTALI, M. (ed.) (2010). Sport et médias. Biarritz: Atlantica.

BARBEIRO, H.; RANGEL, P. (2006): Manual do jornalismo esportivo. Sâo Paulo: Contexto.

BARRERO, J. (2008). Periodistas deportivos contra la violencia en el fútbol, al pie de la letra. Madrid: Fragua. (2009). Protagonistas contra la violencia en el deporte. Madrid: Fragua. (2010). SDF, Solo deporte femenino. Madrid: Fragua.

BAZÁN, L. J. (2003). Diseño de un diccionario con términos técnicos y frases aplicadas en el periodismo deportivo. Caso específico: el béisbol venezolano. Tesina de Licenciatura, Universidad Fermín de Toro.

BLECUA, J. M. (coord.) (2007). Lengua Castellana y Literatura. Tercer Curso de ESO. Madrid: SM, colección Enlace.

BOYLE, R.; HAYNES, R. (2009). Power Play: Sport, the Media and Popular Culture. Edimburgo: Edinburgh University Press.

CALVI, M. V.; CHIERICHETTI, L. (eds.) (2006). Nuevas tendencias en el discurso de especialidad. Berna: Peter Lang.

CARRIAZO, J. R. (2008). "Libros de estilo y diccionarios de dudas: brújulas para orientar al profesional de la lengua en la norma policéntrica del español". En FERNÁNDEZ, P.; BLANCO, I. (coords.) (2008). Diccionarios y libros de estilo. Madrid: Fragua, p. 213-231.

CASPISTEGUI, F. J.; WALTON, J. K. (eds.) (2001). Guerras danzadas. Fútbol e identidades locales y regionales e Europa. Pamplona: Eunsa.

CASTAÑÓN, J. (2009). "Idioma, universalización y deporte". Comunicación y deporte en la era global, Universidad de Málaga, Marbella, 7 de agosto (paper). (2011). La comunicación deportiva y la lengua española. Valladolid. 
CASTAÑÓN, J.; RODRÍGUEZ, M. A. (1997). Creación literaria española sobre deporte moderno. Valladolid.

CASTAÑÓN, M. R.; CASTAÑÓN, J. (2006). “Cambios en la redacción periodística del deporte en América y España en el siglo XXI”. En: Revista Digital Universitaria, 76, p. 1-10.

CASTRO, L. (2003). Análisis lingüístico de una muestra del noticiero deportivo. Tesina de Licenciatura, Universidad de La Habana.

CROLLEY, L.; HAND, D. (2002). Football Europe and the press. London: Frank Cass.

DÍAZ, C. (2004). La lengua especial del deporte en los informativos de Telemadrid. Tesina de Licenciatura, Universidad San Pablo-CEU.

DÍAZ, L. (ed.) (2010): Lenguas de especialidad y su enseñanza. Monográficos Marco ELE, $\mathrm{n}^{\mathrm{o}}$ 11. Madrid: Ministerio de Educación y Universidad Internacional Menéndez Pelayo.

DÍAZ, W. (2001). El lenguaje del fútbol en la radio y su incidencia en la hinchada. Tesis de Licenciatura, Universidad Sergio Arboleda.

DULÍKOVÁ, K. (2008). La comparación del lenguaje utilizado en las crónicas de fútbol de los periódicos Abc y El País. Tesina de Licenciatura, Masarykova Univerzita.

ESTEVE, F.; FERNÁNDEZ, J. (2009). Áreas de especialización periodística. Madrid: Fragua.

FERNÁNDEZ, E.; CEREZUELA, B.; GÓMEZ, M.; KENNETT, C.; MORAGAS, M. (2011): Mosaico olímpico. Barcelona: Centre d' Estudis Olímpics.

FUNDACIÓN DEL ESPAÑOL URGENTE (2008). Manual de español urgente. Madrid: Cátedra.

GALFARO, E.; BENGOECHEA, M.; VÁZQUEZ, B. (2010). Hablamos de deporte en femenino y en masculino. Madrid: Instituto de la Mujer.

GÁlVEZ, J. (2007). Lengua Castellana y Literatura. Primer Curso de Bachillerato. Madrid: Mc Graw Hill.

GARCÍA, E. T. (2000). El deporte y sus metáforas. Análisis e influencia del lenguaje deportivo en la prensa española de finales del siglo XX. Tesis doctoral, Universidad Complutense de Madrid.

GARCÍA YEBRA, V. (2003). El buen uso de las palabras. Madrid: Gredos.

GÓMEZ FONT, A. (ed.) (2004). Manual de estilo de la National Association of Hispanic Journalists. Washington: Knight Ridder.

(2006). Donde dice... debiera decir. Gijón: Trea.

GONZÁLEZ, S. A. (2008). El fútbol que no miramos. Sevilla: Visión Libros.

GONZÁLEZ, T. (2010). Manual del narrador deportivo de fútbol. Tesis de Licenciatura, Universidad Panamericana de Guatemala.

GUTIÉRREZ, J. (2006). “¿Y si los anglicismos fueran como las bacterias?”. En DAHMEN, W.; HOLTUS, G.; KRAMER, J.; METZELTIN, M.; SCHWEIKARD, W.; WINKELMANN, O. (coords.) (2006). Lengua, historia e identidad. Perspectiva española e hispanoamericana (Romanistisches Kolloquium, XVII). Tübingen: Günter Narr Verlag, p. 301-339.

HANSSON, M. (2005). El campo fútbol slagfält eller magisk matta? Att översätta bildspraket inom fotbollens värld. Tesis doctoral, Universidad de Estocolmo.

HERNÁN-GÓMEZ, B. (ed.) (2009): Il Linguaggio dello Sport, la Comunicazione e la Scuola. Milán: Edizioni Universitarie de Lettere Economia Diritto.

(2010). "La presencia de la terminología deportiva en un diccionario bilingüe 
español-italiano". En Civil. P. ; Crémoux, F. (eds.) (2010): Actas del XVI Congreso de la Asociación Internacional de Hispanistas. Nuevos caminos del hispanismo... Madrid: Veuvert.

HERRÁEZ, Á. J. (2002). La lengua del ciclismo en francés: análisis semántico y lexicológico. Tesis doctoral, Universidad Complutense de Madrid.

ISASI, A. (2006). La construcción del derbi futbolístico Real Madrid C. F. - F. C. Barcelona en el discurso periodístico de El País y La Vanguardia entre 1996 y 2004. Tesis doctoral, Universidad de Santiago de Compostela.

KATZ, J.-D. L. (1998). Lexique Olympique Multilingue. Chátel-sur-Rolle: Éditions du Goéland-Comité Olympique International.

LAN, W.-C. (2004). El anglicismo en el léxico chino mandarín y en el léxico español: su incidencia en la enseñanza-aprendizaje de español como lengua extranjera. Tesis doctoral, Universidad Complutense de Madrid.

LAVRIC, E.; PISEK, G.; SKINNER, A.; STADLER, W. (eds.) (2008): The Linguistics of Football. Tubingen: Gunter Narr Verlag Tubingen.

LÁZARO CARRETER, F. (2003). El nuevo dardo en la palabra. Madrid: Aguilar.

LLEIXÀ, T.; SOLER, S. (eds.) (2004). Actividad física y deporte en sociedades multiculturales. ¿Integración o segregación? Barcelona: ICE Universitat de Barcelona.

LÓPEZ, P. (2011). Deporte y mujeres en los medios de comunicación. Madrid: Consejo Superior de Deportes.

LORENZO, E. (2008). El observatorio de la lengua. Madrid: Agencia Española de Cooperación Internacional.

LUNZENFICHTER, A. (2004). L'Association Internationale de la Presse Sportive. Biarritz: Atlantica.

MAPELLI, G. (2000). Il linguaggio del calcio nei giornali sportivi italiani e spagnoli. Tesina de Licenciatura, Università degli Studi di Bergamo.

MARCHAND, J. (2002). Les patrons du Tour. Biarritz: Atlantica. (2003). Jacques Goddet, Journaliste d'abord. Biarritz: Atlantica. (2004). Journalistes de sport. Biarritz: Atlantica.

MARÍN, J. (coord.) (2005). Comunicación y deporte. Sevilla: Comunicación Social Ediciones y Publicaciones.

MARRERO, O. (2010). Fundamentos del periodismo deportivo. San Juan: Terranova.

MARTINELL, E. (2004). "Die spanische Sprache und die Sprachen Spaniens". En BERNECKER, W. L.; DIRSCHERL, K. (coords.) (2004): Spanien heute. Frankfurt: Vervuert, p. 533-558.

MARTÍNEZ ALBERTOS, J. L. (2008). "La responsabilidad lingüística de los periodistas". En FERNÁNDEZ, P.; BLANCO, I. (coords.) (2008): Diccionarios y libros de estilo. Madrid: Fragua, p. 21-38.

MEDINA, F. X.; SÁNCHEZ, R. (eds.) (2003): Culturas en juego. Barcelona: Icaria.

MINISTERIO DE CULTURA (2010). XXVI Encuentro de Escritores y Críticos de las Letras Españolas en Verines: Deporte y literatura, hoy. Pendueles, 16 y 17 de septiembre.

MORALES, J. C. (2009). Estudio comparativo del lenguaje retórico utilizado por los narradores y comentaristas de fútbol de Emisoras Unidas y Red Deportiva. Tesis de Graduación, Universidad de San Carlos de Guatemala.

MORELLI, G. (2000). Ludus. Valencia: Pre-Textos.

MORENO, J. G. (2001). El español en América. México, D. F.: Fondo de Cultura 
Económica.

(2003). Suma de minucias del lenguaje. México, D. F.: Fondo de Cultura Económica. (2007). Introducción al español americano. Madrid: Arco Libros.

NAVARRO, C,; RODRÍGUEZ, R. M.; PEZZE, F.; MIOTTI, R. (2008). La comunicación especializada. Berna: Peter Lang.

NOMDEDEU, A. (2004). Terminología de fútbol y diccionarios: elaboración de un diccionario de especialidad para el gran público. Tesis doctoral, Universidad Autónoma de Barcelona.

ORDOÑO, A. (2004). 32 léxicos trilingües de deportes y medios de comunicación para los Juegos Olímpicos y Mediterráneos. Almería: 2004.

ORGANIZACIÓN DEL BACHILLERATO INTERNACIONAL (2007): Guía de la Educación Física, Programa de los Años Intermedios. Cardiff: Organización del Bachillerato Internacional.

PANIAGUA, P. (2009). Cultura y guerra del fútbol. Barcelona: UOC.

PAREDES, J. (2002). El deporte como juego: un análisis cultural. Tesis doctoral, Universidad de Alicante.

PELTZER, F. (2007). Léxico del fútbol. Buenos Aires: Dunken.

PILMARK, K.; HAKANSON, L. (2011). El deporte. Copenhague: Glyldendal Uddannelse.

PREUSS, H.; LIESE K. (eds.) (2011). Internationalism in the Olympic Movement. Wiesbaden: VS Verlag für Sozialwissenschaften.

REAL ACADEMIA ESPAÑOLA (2001). Diccionario de la Lengua Española. Madrid: Espasa Calpe.

(2006). Diccionario Esencial de la Lengua Española. Madrid: Espasa Calpe.

REAL ACADEMIA ESPAÑOLA; ASOCIACIÓN DE ACADEMIAS DE LA LENGUA ESPAÑOLA (2005). Diccionario Panhispánico de dudas. Madrid: Santillana. (2009). Nueva Gramática de la Lengua Española. Madrid: Espasa Calpe.

RIERA, A. (2003). Análisis comparado del uso del deporte en la publicidad televisiva en España. Tesis doctoral, Universitat de Lleida.

RIVERA, E. (2010). Cancha Libre. Hermosillo: Universidad de Sonora.

ROGAN, M,; ROGAN, M. (2011). Britain and the Olympic Games. Leicester: Matador.

ROJAS, J. L. (2005). La información y el deporte: Sevilla: Aconcagua.

(2008). El deporte en los libros de estilo de España e Hispanoamérica. Tesina de Licenciatura, Universidad de Sevilla.

(2010). Bases para la formulación de un libro de estilo de última generación. Construcción de un modelo teórico válido para los medios deportivos escritos digitales en lengua española. Tesis doctoral, Universidad de Sevilla.

(2011). Libros de estilo y periodismo global en español. Valencia: Tirant Humanidades.

RUIZ, J. A. (2010): Fútbol, pan y circo. Madrid: Fragua.

SALVADOR, G. (2006). El fútbol y la vida. Madrid: Unison.

(2007a). Noticias del Reino de Cervantes. Madrid: Espasa.

(2007b). Estar a la que salte. Madrid: Espasa.

SAMPER, D. (2001). “A patadas con la lengua". Segundo Congreso Internacional de la Lengua Española, Valladolid, 17 de octubre (paper).

SÁNCHEZ, M. (2005). Aprender español entrenándose. Milán: Arcipelago.

SCOTINI, P. (2006): Il dizionario del calcio in sei lingue. Milán: Mondadori. 
SECRETARIA DE EDUCAÇÃO CONTINUADA, ALFABETIZAÇÃO E DIVERSIDADE (2007). "Atividade: En Brasil, el fútbol genera muchos puestos de trabajo". En: Cadernos de EJA: materiais pedagógicos para o $1 .{ }^{\circ}$ e o2. ${ }^{\circ}$ segmentos do ensino fundamental de jovens e adultos. Cultura e Trabalho : caderno do profesor. Sâo Paulo: Ministerio da Educação, p. 79.

SOLAR, L. V.; REGUERA, G. (eds.) (2008): Cultura (s) del fútbol. Vitoria: Bassarai.

STASSINET, H. (2002): Hablemos de fútbol en 8 idiomas. Barcelona: Assimil.

STEEN, R. (2008). Sports Journalism. A Multimedia Premier. Londres: Routledge.

TERMCAT (2010). Diccionari general de l'esport. Barcelona: Unió de Federacions Esportives de Catalunya, Govern de les Illes Balears, Conselleria d'Educació i Cultura i Consell Català de l'Esport.

TERUEL, A. (2006). Contribución al estudio del lenguaje del fútbol en la prensa escrita española. Tesis doctoral, Universidad Nacional de Educación a Distancia.

TÉTART, P.; VILLARET, S. (2010). Les voix du sport. Biarritz: Atlantica.

TILLMAN-WELEDA, B. (2008). Anglicisms in Spanish form, a semantic point of view. Múnich: Grin.

URÍA, J. (2009). "Los deportes de masas en los años veinte. Fútbol, élites simbólicas e imágenes de modernidad en España". En SALAÜN, S.; ÉTIENVRE, F (coords.) (2009). La réception des cultures de masse et des cultures populaires en Espagne: XVIIIe-XXe siecles, París, Université de la Sorbonne Nouvelle (Paris III), p. 155-214.

VIGARA, A. M. (coord.) (2009). De igualdad y diferencias: diez estudios de género. Madrid: Huerga \& Fierro.

VILAS, S. (2005). Formaçâo e informaçâo esportiva. Jornalismo para iniciados e leigos. Sâo Paulo: Summus.

WEINRICH, I. (2007). Interkulturelle Beziehungen und Sprachen im Kontakt- der Einfluss des Englischen auf das spanische im Bereich des Sports. Múnich: Grin.

WOOD, D. (2007). "Sport and Latin American Studies". En Bulletin of Spanish Studies: Hispanic Studies and Researches on Spain, Portugal and Latin America, 84, 4, p. $629-643$.

WOOD, D.; JOHNSON, P. L.; MANGAN, J. A.; MAJUMDAR, B.; DYERSON, M. (2008). Sporting Cultures: Hispanic Perspectives on Sport, Text an the Body. Londres: Routledge.

ZORRILLA, A. M. (2004). "La lengua como espectáculo: entre la crónica deportiva y la noticia policial". Tercer Congreso Internacional de la Lengua Española, Rosario, 19 de noviembre (paper).

\section{El autor}

Jesús Castañón Rodríguez es profesor y escritor. Director de Idioma y deporte.com, ha sido colaborador externo en publicaciones de la Real Academia. Entre sus obras destacan: Creación literaria y fútbol (1991), El lenguaje periodístico del fútbol (1993), Diccionario terminológico del deporte (2004), Términos deportivos en el habla cotidiana (2005), Términos deportivos de origen extranjero (2010) y La comunicación deportiva y la lengua española (2011). 